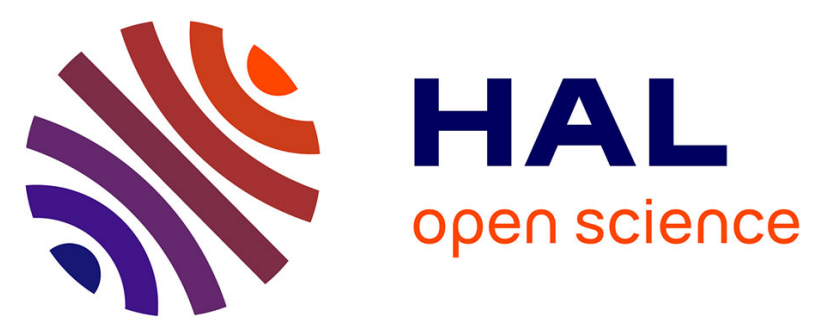

\title{
Structure of protein emulsion in food impacts intestinal microbiota, caecal luminal content composition and distal intestine characteristics in rats
}

Martin Beaumont, Daphné Jaoui, Veronique Douard, Damien Mat, Fanny Koeth, Bénédicte Goustard, Camille Mayeur, Stanislas Mondot, Anais Hovaghimian, Steven Le Feunteun, et al.

\section{To cite this version:}

Martin Beaumont, Daphné Jaoui, Veronique Douard, Damien Mat, Fanny Koeth, et al.. Structure of protein emulsion in food impacts intestinal microbiota, caecal luminal content composition and distal intestine characteristics in rats. Molecular Nutrition and Food Research, 2017, 61 (10), pp.1700078. 10.1002/mnfr.201700078 . hal-01598952

\section{HAL Id: hal-01598952}

https://hal-agroparistech.archives-ouvertes.fr/hal-01598952

Submitted on 26 May 2020

HAL is a multi-disciplinary open access archive for the deposit and dissemination of scientific research documents, whether they are published or not. The documents may come from teaching and research institutions in France or abroad, or from public or private research centers.
L'archive ouverte pluridisciplinaire HAL, est destinée au dépôt et à la diffusion de documents scientifiques de niveau recherche, publiés ou non, émanant des établissements d'enseignement et de recherche français ou étrangers, des laboratoires publics ou privés. 


\section{Structure of protein emulsion in food impacts intestinal microbiota, caecal luminal content}

\section{composition and distal intestine characteristics in rats}

Martin Beaumont ${ }^{1 *}$, Daphné Jaoui ${ }^{2 *}$, Véronique Douard ${ }^{2}$, Damien Mat $^{3,4}$, Fanny Koeth ${ }^{2}$, Bénédicte Goustard $^{2}$, Camille Mayeur ${ }^{2}$, Stanislas Mondot $^{2}$, Anais Hovaghimian ${ }^{2}$, Steven Le Feunteun ${ }^{3}$, Catherine Chaumontet ${ }^{1}$, Anne-Marie Davila ${ }^{1}$, Daniel Tomé ${ }^{1}$, Isabelle Souchon ${ }^{3}$, Camille Michon ${ }^{4}$, Gilles Fromentin ${ }^{1}$,

François Blachier ${ }^{1}$, Marion Leclerc ${ }^{2}$

${ }^{1}$ UMR PNCA, AgroParisTech, INRA, Université Paris-Saclay, 75005, Paris, France

${ }^{2}$ UMR1319, MICALIS, AgroParisTech, INRA, Université Paris-Saclay, 78350, Jouy-en-Josas, France

${ }^{3}$ UMR GMPA, AgroParisTech, INRA, Université Paris-Saclay, 78850, Thiverval-Grignon, France

${ }^{4}$ UMR Ingénierie Procédés Aliments, AgroParisTech, INRA, Université Paris-Saclay, 91300, Massy,

France

*: these authors contributed equally to the work

\section{Key words}

Amino acid transporters, bacterial metabolites, food structure, gut microbiota, gut peptides.

\section{Correspondence}

Marion Leclerc, INRA, AgroParisTech, Université Paris-Saclay, MICALIS, Building 442, Domaine de Vilvert, 78352 Jouy-en-Josas, INRA, marion.leclerc@inra.fr

Received: 23/01/2017; Revised: 10/04/2017; Accepted: 25/04/2017

This article has been accepted for publication and undergone full peer review but has not been through the copyediting, typesetting, pagination and proofreading process, which may lead to differences between this version and the Version of Record. Please cite this article as doi: 10.1002/mnfr.201700078.

This article is protected by copyright. All rights reserved. 


\section{Abbreviations}

AA: Amino acid

CKK: cholecystokinin

GCE: gelled coarse emulsion

GIP: gastric inhibitory peptide

GLP-1: glucagon-like peptide-1

LFE: liquid fine emulsion

MM: Mucus-associated microbiota

NEFA: non esterified fatty acids

OTU: Operating Taxonomy Unit

PYY: peptide YY

qPCR: quantitative PCR

SCFA: short chain fatty acid

\section{ABSTRACT}

Scope: Few studies have evaluated in vivo the impact of food structure on digestion, absorption of nutrients and on microbiota composition and metabolism. In this study we evaluated in rat the impact of two structures of protein emulsion in food on gut microbiota, luminal content composition, and intestinal characteristics.

Methods and results: Rats received for 3 weeks two diets of identical composition but based on lipid-protein matrices of liquid fine (LFE) or gelled coarse (GCE) emulsion. LFE diet led to higher abundance, when compared to the GCE, of Lactobacillaceae (Lactobacillus reuteri) in the ileum, higher $\beta$-diversity of the caecum mucus-associated bacteria. In contrast, the LFE diet led to a decrease in Akkermansia municiphila in the caecum. This coincided with heavier caecum content and higher amount of isovalerate in the LFE group. LFE diet induced an increased expression of i) amino acid transporters in the ileum ii) glucagon in the caecum, together with an elevated level of GLP-1 in This article is protected by copyright. All rights reserved. 
portal plasma. However, these intestinal effects were not associated with modification of food intake or body weight gain.

Conclusion: Overall, the structure of protein emulsion in food affects the expression of amino acid transporters and gut peptides concomitantly with modification of the gut microbiota composition and activity. Our data suggest that these effects of the emulsion structure are the result of a modification of protein digestion properties.

Few studies have evaluated, in vivo, the impact of food structure on health. The present study is among the first ones demonstrating that the structure of protein emulsion impacts microbiota and nutrient handling all along the distal gastro intestinal tract in rats. In the future, for populations at risk or deficient, it might be possible to process food to deliver specific nutrients to the gut.

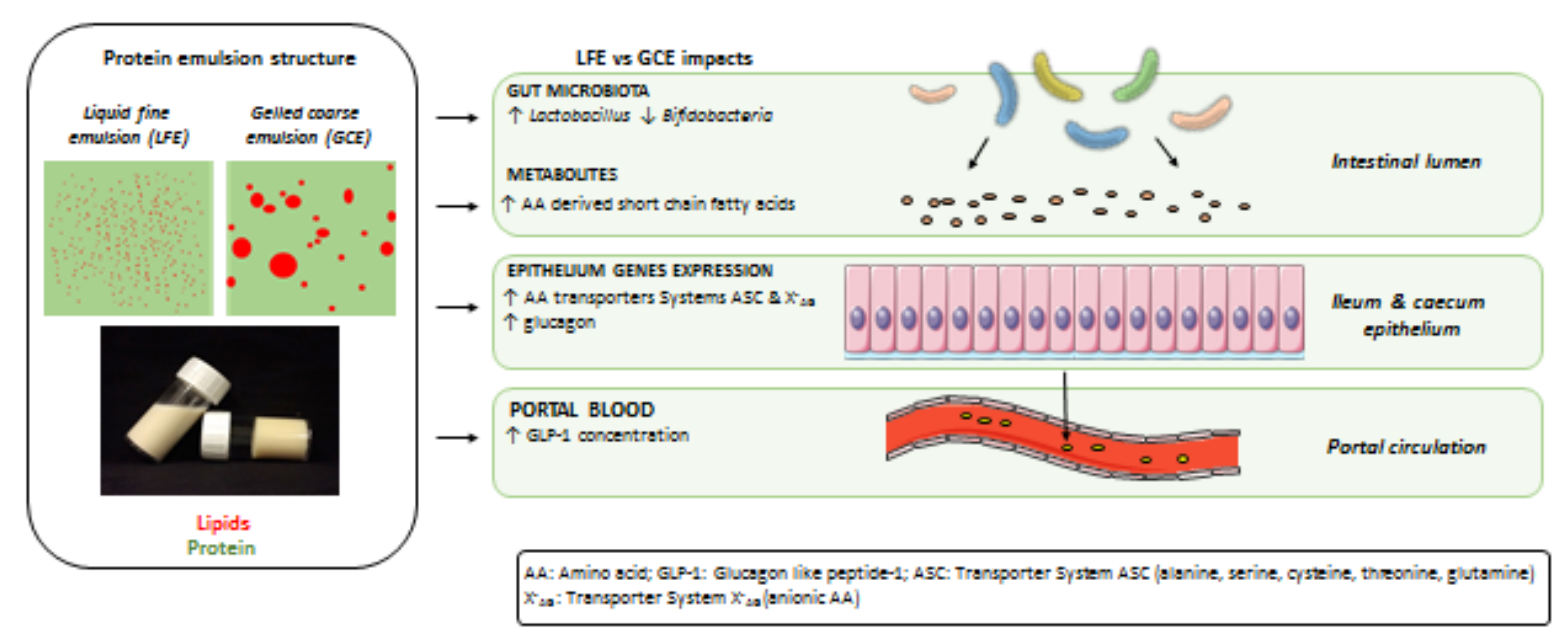

This article is protected by copyright. All rights reserved. 


\section{Introduction}

A substantial fraction of western diet incorporates processed or reconstituted food, which may alter the ingredient structure without substantially changing the composition of the food. The spatial arrangement of food constituents (food structure) is notably determined by food processing and regulates digestion mostly through modifications of the accessibility of digestive enzymes [1]. Food structure has been mostly studied by in vitro digestion, however, few in vivo published studies showed that food structure may regulate transit time, nutrient sensing and absorption in the gastrointestinal tract as well as satiety and post-prandial metabolism [2]. For instance, in humans a coarse fat emulsion delivered intra-gastrically, decreased lipolysis in the duodenum relatively to a fine fat emulsion [3]. In intra-duodenal infusion experiments in humans, an increase in the fat emulsion droplet size induced a decrease in the lipid absorption rate together with an increase in the release of the gut peptides cholecystokinin (CCK) and peptide YY (PYY) associated with satiety increase [4]. In mini-pigs, gelation of milk protein slowed down amino acid (AA) absorption with little consequences on the gut peptides CCK and ghrelin [5]. Mice fed for 18 weeks a standard powder diet display increased body weight and fat mass owing to an increased food intake relative to mice fed an identical diet in pellets, indicating a crucial role of diet macrostructure on food consumption [6].

Since food structure may affect digestive processes, it might modify the quantity and quality of dietary compounds available in the lower gastrointestinal tract [7] which is colonized by the gut microbiota [8-10]. In the pig model, diet macrostructure (fine versus coarsely ground) regulated gut microbiota composition and total short chain fatty acids (SCFA) concentrations [11] suggesting modifications of microbial metabolic activity. However, despite the crucial role of the gut microbiota in nutrition and health $[12,13]$, the effects of food structure on intestinal ecosystems have so far been widely neglected. The microbiota composition and metabolic activity have been shown to participate in the regulation of digestion, nutrients transport, satiety and host metabolism [14]. Therefore, food structure may impact host digestive physiology and metabolism notably through regulation of the gut microbiota.

Recently, we have designed two lipid-protein matrices of identical composition but with one being finely emulsified (liquid fine emulsion, LFE) while the other one was coarsely emulsified and This article is protected by copyright. All rights reserved. 
heated for gelation (gelled coarse emulsion, GCE) resulting in two matrices differing both in microstructure (fat droplet diameter ratio GCE / $\mathrm{LFE}=26.5$, soluble $v s$ crosslinked proteins) and macroscopic properties (liquid or gelled) [15]. In vitro, the initial rate of both proteolysis and lipolysis are slower for GCE than for LFE (related to the gel state of GCE), while the extent of lipolysis is higher in LFE (related to the fat droplets small size) and the extent of proteolysis is higher in GCE (related to the denaturation of protein during heat treatment) [15]. In this context, the objective of the present study was to evaluate in rats the effect of LFE or GCE consumption on the gut microbiota composition and activity, nutrient sensing and transport, food intake and metabolism.

\section{Materials and methods}

\subsection{Lipid-protein matrices preparation}

LFE and GCE were prepared as previously described [15]. Both matrices had identical composition (10 wt \% rapeseed oil (Lesieur) and 15 wt \% whey proteins isolate, Prolacta 95 (Lactalis)). Briefly, LFE was obtained by emulsification with a rotor-stator homogenizer and treatment with ultra-sound. GCE was obtained by emulsification with a rotor-stator homogenizer and heating at $70^{\circ} \mathrm{C}$ for 5 min. GCE was chopped for $3 \mathrm{sec}$ with a kitchen food grinder (Braun Turbo $600 \mathrm{~W}$ type 4191) to produce pieces ranging from 3 to $5 \mathrm{~mm}$. Both matrices were then frozen at $-80^{\circ} \mathrm{C}$ and freeze-dried. Differential in vitro digestion properties of the two matrices were not affected by the freeze-drying rehydration process (unpublished data).

\subsection{Animals and experimental design}

The present protocol received the authorization from the «Ministère de l'Éducation Nationale, de l'Enseignement Supérieur et de la Recherche » (APAFIS \# 4179-2016021609463495 v2). For details, see Supplementary Information. Briefly, sixteen male Wistar Han rcc rats (Harlan, Gannat, France) weighing $190 \mathrm{~g}$ ( 7 weeks) received during 3 weeks the diet described in Table 1, with all proteins and lipids included in the LFE $(n=8)$ or in the GCE $(n=8)$. Freeze-dried LFE and GCE were gently homogenized with the powders of the other ingredients of the diet, and water was added to obtain a dough texture. Body weight and food intake were measured daily. After 3 weeks, rats were This article is protected by copyright. All rights reserved. 
anesthetized with pentobarbital (40 $\mathrm{mg} / \mathrm{kg}$ body weight). Portal and peripheral blood, intestinal contents (small intestine, caecum and colon), caecum mucus-associated microbiota (MM), intestinal sections (duodenum, ileum, jejunum, caecum and colon), liver and adipose tissues were collected.

\subsection{Analysis of intestinal contents}

For calculation of water content, $0.1 \mathrm{~g}$ of caecum and colon contents was weighted before and after 24 hours at $50{ }^{\circ} \mathrm{C}$. Caecal and colonic contents homogenates were obtained by vigorous homogenization in ultrapure water followed by centrifugation $\left(14000 \mathrm{~g}, 15 \mathrm{~min}, 4^{\circ} \mathrm{C}\right)$. SCFA in the homogenates or in portal serum were then derivatized by esterification and analyzed by gas chromatography as previously described [16]. For ammonia measurement, the intestinal content homogenates were filtered with nanosep 30K (Pall) and ammonia concentration was measured using the ammonia assay kit (Megazyme) according to manufacturer instructions. Sulfide was quantified by gaschromatography mass-spectrometry in intestinal contents as previously described [17]. Cysteine desulfhydrase and urease activity were measured in bacterial lysates from the caecal contents (see Supplementary Information).

\subsection{Microbiota analysis}

$D N A$ extraction and quantitative PCR (qPCR): Total DNA was extracted from $\sim 150 \mathrm{mg}$ of ileum content, caecum contents, MM samples, re-suspended in Tris EDTA $(50-100 \mu \mathrm{L})$ and stored at $-20^{\circ} \mathrm{C}$ as previously described $[10,18]$. For MM samples, an overnight isopropanol incubation was added. DNA concentration and integrity were assessed by spectrophotometry using a Nanodrop 1000 (Thermoscientific) and by electrophoresis on agarose gel $1 \% \mathrm{w} / \mathrm{v}$ with $\mathrm{EtBr}(1 \mu 1 / \mathrm{ml})$. qPCR was performed as described previously [19-22] (see Supplementary Information).

$16 S$ rDNA sequencing and analysis: PCR targeting the V3-V4 regions of the 16S rDNA genes (probes used: V3F-TACGGRAGGCAGCAG-342, E. coli position, V4RATCTTACCAGGGTATCTAATCCT-806, E. coli position) were performed as previously described [23] on all the DNA extracted in this study. PCR mixes were assembled as follows: $22 \mu \mathrm{L}$ of reaction mix (AccuPrime ${ }^{\mathrm{TM}}$ Pfx DNA Polymerase, $0.05 \mathrm{U} / \mu \mathrm{L}, 10 \mathrm{X}$ PCR buffer minus $\mathrm{Mg}$ and $\mathrm{H}_{2} \mathrm{O}$ ), $2 \mu \mathrm{L}$ of This article is protected by copyright. All rights reserved. 
BC primers (800nM) and DNA (Caecum 100 ng, Mucosa 100-200 ng, Ileum 200-300 ng). Amplicons were purified and normalized as described (Supplementary Information) and sequenced with the Miseq ${ }^{\circledR}$ sequencing technology (Illumina) at the Institut Curie NGS platform. Paired-end reads obtained were merged using FLASH v1.2.11 software (parameters: -m 20; -M 170; -x 0.25; PHRED 33) [24]. Reads with length $\geq 400 \mathrm{pb}$ were kept for downstream analysis. The merged sequences were processed with QIIME v1.9.0 [25], (see Supplementary Information for bioinformatics pipeline). In ileum, caecum and MM, the average number of OTUs was 870,1190, 1204 respectively. Supporting Information Table S1 provides the detailed sequencing results.

\section{5 mRNA quantification in intestinal mucosa}

Total RNA was isolated from intestinal section using mirVana ${ }^{\circledR}$ miRNA isolation kit according to the manufacturer's instructions (Ambion, France). Reverse transcription was performed with $5 \mu \mathrm{g}$ total RNA using High capacity cDNA Reverse Transcription kit (Applied Biosystems, Foster City, CA) in a final volume of $25 \mu 1$. Real-time PCR was performed based on TaqMan gene expression assays with predesigned Taqman primers and probes for the Rat (Assays-on-Demand ${ }^{\mathrm{TM}}$, Gene Expression Products; Applied Biosystems) (Supporting Information Table S4), $\beta$-actin being the housekeeping gene to normalize the mRNA abundance of each target gene. Expression values of target genes were calculated based on the comparative threshold cycle $(\mathrm{Ct})$ method to generate $\Delta \mathrm{Ct}$ values. The relative abundance of each mRNA in each sample was then normalized according to the equation: Relative Quantity RQ $=2^{-\Delta \Delta \mathrm{Ct}}[26]$.

\subsection{Plasma and lipid analysis}

Peripheral plasma was analyzed for glucose, triglycerides, total cholesterol, HDL and non-esterified fatty acids (NEFA) by AU 400 automated biochemical analyzer (Olympus). Glucagon-like peptide-1 (GLP-1) level was determined by ELISA (Millipore) using $100 \mu$ of portal plasma diluted 1:5. Lipids collected from liver, fat tissues and diet were analyzed (see Supplementary Information).

This article is protected by copyright. All rights reserved. 


\subsection{Statistical analysis}

For microbiota qPCR data, log median values were compared with non-parametric Wilcoxon-MannWhitney test using R software (http://www.R-project.org/) 16S rDNA sequencing data were analyzed using the Phyloseq package in R [27]. Effect of emulsion structure on microbiota composition was tested using a linear model with the DESeq2 analysis pipeline (Supplementary Information). For all the other parameters, Mann-Whitney test was performed using GraphPad Prism Version 6.02 for Windows (GraphPad Software). Differences with $p$-values $<0.05$ were considered as statistically significant.

\section{Results}

\subsection{Emulsion structure modifies the microbiota in the ileum, caecum and caecum mucus}

To address the effects of emulsion structure on the microbiota in the distal gastro-intestinal tract we first investigated the effects of the LFE and GCE diets on the ileum bacterial population (Figure 1, Supporting Information Tables S1, S2 and S3). The qPCR analysis showed that the total bacterial concentration in the ileum, $4.10^{7}$ cell $/ \mathrm{g}$, was similar between the two groups. However, the concentration of the dominant Lactobacillus group was significantly higher in the LFE group relative to the GCE group (Figure 1). In contrast, the Bifidobacteria concentration tended $(p=0.06)$ to be lower in the LFE group than in the GCE group (Figure 1). To address the ecosystem composition at a broader level we performed $16 \mathrm{~S}$ rDNA sequencing. The microbiota in the ileal content was mainly composed of the Firmicutes (mainly Lactobacillaceae) and Proteobacteria phyla (Figure 2, A). The sequencing confirmed that, the Lactobacillaceae family in the ileum, was more abundant under LFE than GCE diet (Figure 2, B). Within this family, Lactobacillus reuteri and an unknown species were over-represented in rat fed the LFE diet (Figure 2, B inset).

We next examined bacterial populations in the caecum content. The caecum content weight was significantly increased in rats fed LFE when compared to rats fed GCE diet, while water and solid matter content being proportionally increased (Table 2). qPCR analysis showed that the total bacterial concentration in the caecal content was $2.10^{9} \mathrm{cell} / \mathrm{g}$, whatever the diet (Figure 1). Bifidobacteria This article is protected by copyright. All rights reserved. 
concentration was lower with the LFE diet, while there was only a trend $(\mathrm{p}=0.10)$ toward a higher concentration of Lactobacillus group in the rats caecum (Figure 1). 16S rDNA sequencing data pointed at several distinctive features between the two diets. Interestingly, the rare Verrucomicrobia phylum was significantly less abundant in the caecum content of rats fed the LFE, when compared to the GCE diet, and this was related to a lower abundance of the mucin-degrader Akkermansia muciniphila (Figure 3, A). In the Firmicutes phyla, the Coprococcus genus (Lachnospiraceae family) was more abundant in the caecum content of rats fed the LFE (Figure 3, B).

Since bacteria in the mucus layer have a more direct interaction with the epithelial cells, we next analyzed the effects of the two diets on the caecum MM. The qPCR showed, again, that the diet did not modify the total bacterial concentration. However, it also indicated that bacterial load was similar in the mucus and the lumen content (Figure 1). Furthermore, under LFE diet, Bifidobacteria and Lactobacillus groups were lower and higher, respectively (Figure 1). Strikingly, the caecum mucus was the only compartment where bacterial $\beta$-diversity showed a strong segregation according to the diet (Figure 4, A), indicating a distinct ecosystem structure. Within the Firmicutes, the abundance of the genus Coprococcus (Lachnospiraceae family) was higher with the LFE diet (Figure 4, B). In addition, the abundance of 27 "non dominant' OTUs $(<1 \%)$ were significantly affected by the diet (Supporting Information Table S3). In the Firmicutes, 6 OTUs from the Oscillispira and unknown genera were less abundant in the LFE group than in the GCE group (Figure 4, C). Within the Bacteroidetes, 9 OTUs from the Bacteroides, Parabacteroides or Prevotella genera but also from unknown families of the Bacteroidales order were impacted, with one unknown OTUs from undetected under LFE to $1 \%$ of the sequences counts with GCE diet (Figure 4, D).

\subsection{Emulsion structure modifies the caecal luminal bacterial metabolite composition}

In caecum, the total SCFA quantity was similar in both LFE and GCE fed rats (Table 2). The total quantity of caecal SCFA resulting from bacterial metabolism of both carbohydrates and AA (including acetate, propionate and butyrate) was similar in LFE and GCE fed rats (Table 2). In contrast, the total quantities of AA-derived SCFA (isobutyrate, isovalerate and valerate) were more abundant in the caecum of LFE fed rats when compared to GCE fed rats (Table 2). This accumulation This article is protected by copyright. All rights reserved. 
of AA-derived SCFA was mostly driven by a significantly higher amount of isovalerate in the caecum of LFE fed rats (Table 2). In the caecum, the quantities of ammonia and sulfide, two metabolites derived from bacterial amino acid metabolism were however not impacted by the emulsion structure. The total enzymatic activity of bacterial cysteine desulfhydrase and urease were slightly but significantly higher in the caecum of rats fed LFE when compared to GCE (Table 2). None of the parameters described in this paragraph were modified in the colon (data not shown) indicating that the effects of the emulsion structure on microbial metabolic activities were restricted to the caecum. Acetate, the major microbiota-derived SCFA present in the portal blood, displayed similar concentrations whatever the diet $(0.52 \pm 0.14$ and $0.35 \pm 0.10 \mathrm{mM}$ in LFE and GCE fed rats, respectively).

\subsection{Emulsion structure regulates expression of AA transporters in the small intestine and gut peptide in the caecum}

Dietary composition and the resulting luminal content are important modulators of nutrient intestinal transport systems and gut peptide release. Thus, we firstly investigated the impact of LFE and GCE diets on AA and lipids transporters. In the duodenum and jejunum, the expression levels of all apical AA and peptide transporters was similar in both LFE and GCE groups (Table 3). Only the basolateral system A displayed a lower expression level in the duodenum of the LFE fed rats. In contrast, in the ileum the expression of 2 apical AA transporters (the system ASC and the system $\mathrm{X}^{2-}{ }_{\mathrm{AG}}$ ) were increased significantly in the LFE fed rats when compared to the GCE fed rats. On the other hand, LFE and GCE did not affect the expression level of the main lipid transporters and lipid metabolismrelated enzymes along the gastrointestinal tract (Supporting Information Table S5). Next, we determined the effect of the two diets on gut peptide expression. In the small intestine (Supporting Information Table S6) the emulsion structure did not change the level of expression of gastric inhibitory peptide (GIP), CCK, glucagon, PYY and somatostatin. However more distally in the caecum, but not in the colon, the expression level of glucagon was increased in the LFE fed rat when compared to GCE fed rat (Figure 5, A). This increase in caecal glucagon gene expression was associated with an elevated portal level_of GLP-1 in the LFE fed rats (Figure 5, B). In contrast, in the This article is protected by copyright. All rights reserved. 
caecum and the colon the gene expression of PYY remained unchanged in both groups of rats (Figure $5, \mathrm{C})$.

\subsection{Emulsion structure has no effect on food intake, body weight, body composition and plasma metabolite concentration}

After 3 weeks of consumption of the LFE or GCE diet, cumulated food intake, body weight gain, adipose tissue weight and adiposity were similar in both groups (Table 4). Plasma levels of glucose, triglycerides, cholesterol and HDL were similar in both LFE and GCE rats (Table 4). However, the NEFA levels were reduced by $50 \%$ in the plasma of LFE fed rats. Liver and adipose tissue lipid content (data not shown) and fatty acid profile were similar in both groups (Supporting Information Table S7).

\section{Discussion}

In this study we demonstrated that the structure of two non obesogenic diets of identical composition can itself significantly impact nutrient handling and microbial composition and activity along the lower gastro intestinal tract. The Figure 6 highlights the main significant results of this study: the LFE of lipid-protein strongly modified the microbiota and increased the expression of AA transporter systems in the ileum. In the caecum, LFE diet enhanced the isovalerate total quantity, a branchedchain fatty acid produced by the microbiota from leucine. LFE diet also increased glucagon gene expression in the caecum mucosa and led to an elevated circulating level of portal GLP-1 and reduced NEFA concentration in the plasma. These results can be interpreted in the light of our previous in vitro studies [15], showing that the emulsion structure might affect the digestion rate of lipids and protein. By this latter process, LFE diet may modulate the quantity and quality of dietary compounds available in the lower part of the gastrointestinal tract thus impacting the bacteria and epithelial cells specifically in the distal compartments of the gut (ileum and caecum).

LFE-diet did strongly modify the gut microbiota composition in the ileum by increasing the relative abundance of so far unknown Lactobacillus species, and of Lactobacillus reuteri, a probiotic species [28]. Such an increase in Lactobacillus and lower abundance of Bifidobacteria was found consistently This article is protected by copyright. All rights reserved. 
in the ileum and in the caecum. Interestingly, high-protein diet in humans, pigs and rats also decreased Bifidobacteria and/or increased Lactobacillus abundances [29-31]. Therefore, LFE diet seems to replicate some of the effects of high-protein diets, which are related to a greater peptides supply in the distal part of the gut. In agreement with this proposition, LFE diet induced an increase in isovalerate quantity in the caecum. Isovalerate is a branched-chain fatty acid exclusively originating from the catabolism of leucine and is considered as a marker of microbial protein fermentation [32-34]. Furthermore, isovalerate is produced from leucine, an amino acid known as abundant in whey proteins, the ones used in this study. In humans, up to $12-18 \mathrm{~g}$ of proteins from dietary and endogenous origins can reach the colon each day [35], leading to amino acid release and metabolism by the microbiota $[36,37]$, but the impact on human health of bacterial proteolysis remains unclear [33, 38-40]. Despite being understudied, proteins and byproducts of their breakdown can be energy sources for the bacteria and they also act as substrates or signal molecules for the epithelial cells. It is noteworthy that the total amount of two other AA derived bacterial metabolites, ammonia and hydrogen sulfide, were not different according to the diet structure, despite higher activities of cysteine desulfhydrase and urease in the caecum of LFE animals. This is likely due to the fact that ammonia is known to be efficiently and rapidly transported across the large intestine epithelium [41, 42] and that hydrogen sulfide easily and rapidly penetrates the biological membranes [43]. The increased caecal protein fermentation after LFE diet consumption may result from a modification of the transit time of the intestinal content, but also from an increased bacterial metabolic capacity for protein and amino acid disposal. Members of Lactobacillus and Bifidobacteria genera, commonly used as probiotics and shown to be beneficial for metabolic health [44], are also known to present proteolytic activities [33].

Interestingly, Coprococcus was also more abundant in the caecum under LFE diet. This genus is highly prevalent in the feces [10] or gut biopsies of healthy humans [45]. In addition, the use of Lactobacillus reuteri as a probiotics led to a significant increase of both Lactobacillus and Coprococcus in newborn microbiota [46]. Recently, Coprococcus species have been shown to produce short chain fatty acids from lactate that typically originates from Lactobacillus species [47]. In the first enumeration [48] and further description of the genus in 1974, Coprococcus catus was This article is protected by copyright. All rights reserved. 
shown to produce isovalerate. Whether species from the Coprococcus genus can be proteolytic, or are engaged in synthrophic interactions with the proteolytic Lactobacillus species, remains to be investigated.

Interestingly, the emulsion structure modified the microbiota structure in the caecum mucosa in distinct ways. On a quantitative aspect, it recapitulated the effects seen in the ileum and the caecum, an increased biomass of Lactobacillus, Coprococcus, and a decreased of Bifidobacteria group. In addition, the bacterial $\beta$-diversity reflected diet-based dissimilarity, distinct ecosystem structures, consistent with $\beta$-diversity in human presenting a faster transit time [49]. Finally, some unknown genera and OTUs were significantly impacted in the caecum mucus, reflecting that a number of functional aspects of mucus associated-microbiota remain unknown.

A striking result of the present study is the decreased abundance of Akkermansia muciniphila in the caecum of rats fed the LFE diet when compared to rats fed the GCE diet. This bacterial species is the only known member of the Verrucomicrobia phylum in the intestinal ecosystem [50] and has been positively correlated with beneficial metabolic outcomes in humans [51]. In animal models, administration of $A$. muciniphila counteracts the detrimental metabolic effects of a high-fat diet through the reinforcement of the intestinal barrier function [52]. Moreover, A. muciniphila presence in human and rodent is inversely correlated with body weight [52]. This bacterium is a mucin utilizer, mucin being composed of glycoprotein [53]. However, in our experiments, neither mucins mRNA MUC1 and MUC2 expression in the caecum (data not shown), nor A. muciniphila in mucosa, were modified suggesting an alternative mechanism for the modification of its abundance in caecum content. Interestingly, A. muciniphila has been shown to be more prevalent in humans with slow transit time [54] reinforcing the view that emulsion structure is likely to have impacted transit time. Moreover, it is conceivable that few dietary proteins reached the caecum in rats fed the GCE diet, bringing an ecological advantage to bacterial groups such as A. muciniphila able to use endogenous protein (mucins) as nitrogen source.

Moreover, in porcine intestinal epithelial cells line, the addition of leucine up-regulated expression of Slcla5, a gene that encodes for transport system ASC for neutral amino acids [55], in accordance with 
the present results which show increased expression of this latter gene in rats fed LFE diet. Thus, this supports our two aforementioned hypotheses: an increase AA supply in the ileum/caecum with the LFE diet and/or a longer transit time in the caecum that has been associated with increased protein degradation by the gut microbiota [56]. In addition to Slcla5, LFE diet increased the expression of the Slclal gene (encoding for $\mathrm{X}_{\mathrm{AG}}^{-}$transport system) in the ileum, while the expression of this amino acid transporter remained unchanged in the duodenum and jejunum, indicating a specific effect on the distal part of the small intestine. In the intestine, AA transporters are expressed along the small intestine and each transport system has its own specific expression profile in the gut [57]. PET1, which remained unchanged between the LFE and GCE diets, is mostly expressed in the proximal region of the small intestine likely as a way to allow the rapid absorption of di and tri-peptides in the proximal GI tract [57]. However, for most of the AA transport system, expression increases from the duodenum to ileum likely reflecting the gradual release of AA into the lumen by the proteolysis. The expression of AA transporters is known to be increased during high-protein diet and repressed during low-protein diet through AA sensing [58]. Then, our results suggest that the release of AA was shifted from the proximal small intestine to the ileum with the LFE diet when compared to the GCE diet. Moreover, proteins denaturation during GCE preparation might increase the extent of proteolysis when compared to the LFE, consistently with our in vitro study [15]. The gelled structure of the GCE might also have increased the gastric residence time [5], thereby increasing protein digestion by pepsin and resulting in a more proximal release of AA. In contrast, the emulsion structure had no effects on lipids transporters in the small intestine suggesting differential effects between macronutrients within the same matrix.

In the present study, the rat fed LFE diet displayed an increased glucagon gene expression in the caecum associated with an elevated portal level of GLP-1. The endocrine peptide GLP-1 is produced by L-cells whose population increased toward the distal compartments of the gastrointestinal tract (jejunum $>$ ileum $>$ colon). Among the various AA released during proteins digestion, L-glutamine has been described in vivo as activating the secretion of GLP-1 [59]. Others AA such as glycine and alanine are also potent activator of GLP-1 secretion on the enterotendocrine cell line GLUTag [60]. Alanine and glutamine are transported by the ASC system. As mentioned This article is protected by copyright. All rights reserved. 
previously, the increased ASC system expression in the ileum likely reflects an increase AA supply in the ileum/caecum with the LFE diet. Thus, a higher amount of AA in the distal intestine is indeed expected to stimulate the large number of GLP-1 secreting cells present at the distal level [61].

In addition, the emulsion structure might have modulated the kinetics and the anatomical site of peptides, AA and none esterified fatty acids release in the gut, all of them stimulating the release of GLP-1 by L-cells [62]. The LFE diet induced decrease in plasma NEFA concentration might be mediated through GLP-1 [63]. However, we did not observe any effects of the emulsion structure on glycemia, triglycerides, cholesterol, food intake, and body composition. It is important to consider that in the present study the experimental diets were not obesogenic and that the rats were exposed to the two diets for only three weeks. Further experiments are needed to determine if the effect of emulsion structure that we observed would modulate the metabolic outcomes of diets high in fat or with high saturated fatty acid content.

\section{Concluding remarks}

In conclusion, the present study is among the first ones demonstrating that the structure of protein emulsion impacts microbiota and nutrient handling all along the distal gastro intestinal tract in rats. The LFE diet, in comparison with the GCE diet, modifies the composition and the metabolic activity of the gut microbiota, increasing the caecal content weight and the concentration of isobutyrate, indicating an increased bacterial protein fermentation in this content. These results are likely to be related to a modification of the transit time and of the nutrient release kinetics in the gastrointestinal tract according to the emulsion structure. Similar mechanisms are probably involved in the alteration of the expression of AA transporters and of GLP-1 production induced by the experimental diets. "Food constituents when incorporated to the diet may lead to different structures that will themselves impact the gut microbiota and the animal physiology. One can hypothesize that studies aiming at investigating the addition of a given compound in the diet might combine the effect of the compound itself with the obtained chow structure versus the control one without the compound". Thus, our study reinforces the view that food structure is an important parameter, which impacts microbiota composition and some aspects of host intestinal physiology.

This article is protected by copyright. All rights reserved. 


\section{References}

[1] Norton, J. E., Gonzalez Espinosa, Y., Watson, R. L., Spyropoulos, F., Norton, I. T., Functional food microstructures for macronutrient release and delivery. Food \& function 2015, 6, 663-678.

[2] Wahlqvist, M. L., Food structure is critical for optimal health. Food \& function 2016, 7, 1245-1250. [3] Armand, M., Pasquier, B., Andre, M., Borel, P., et al., Digestion and absorption of 2 fat emulsions with different droplet sizes in the human digestive tract. The American journal of clinical nutrition 1999, 70, 1096-1106.

[4] Seimon, R. V., Wooster, T., Otto, B., Golding, M., et al., The droplet size of intraduodenal fat emulsions influences antropyloroduodenal motility, hormone release, and appetite in healthy males. The American journal of clinical nutrition 2009, 89, 1729-1736.

[5] Barbe, F., Menard, O., Le Gouar, Y., Buffiere, C., et al., The heat treatment and the gelation are strong determinants of the kinetics of milk proteins digestion and of the peripheral availability of amino acids. Food chemistry 2013, 136, 1203-1212.

[6] Yan, L., Combs, G. F., Jr., DeMars, L. C., Johnson, L. K., Effects of the physical form of the diet on food intake, growth, and body composition changes in mice. Journal of the American Association for Laboratory Animal Science : JAALAS 2011, 50, 488-494.

[7] Chacko, A., Cummings, J. H., Nitrogen losses from the human small bowel: obligatory losses and the effect of physical form of food. Gut 1988, 29, 809-815.

[8] Lepage, P., Leclerc, M. C., Joossens, M., Mondot, S., et al., A metagenomic insight into our gut's microbiome. Gut 2013, 62, 146-158.

[9] Tap, J., Mondot, S., Levenez, F., Pelletier, E., et al., Towards the human intestinal microbiota phylogenetic core. Environmental microbiology 2009, 11, 2574-2584.

[10] Qin, J., Li, R., Raes, J., Arumugam, M., et al., A human gut microbial gene catalogue established by metagenomic sequencing. Nature 2010, 464, 59-65.

[11] Canibe, N., Hojberg, O., Hojsgaard, S., Jensen, B. B., Feed physical form and formic acid addition to the feed affect the gastrointestinal ecology and growth performance of growing pigs. Journal of animal science $2005,83,1287-1302$.

[12] Tremaroli, V., Backhed, F., Functional interactions between the gut microbiota and host metabolism. Nature 2012, 489, 242-249.

[13] Portune, K. J., Benitez-Paez, A., Del Pulgar, E. M., Cerrudo, V., Sanz, Y., Gut microbiota, diet, and obesity-related disorders-The good, the bad, and the future challenges. Molecular nutrition \& food research 2016.

[14] Woting, A., Blaut, M., The Intestinal Microbiota in Metabolic Disease. Nutrients 2016, 8, 202.

[15] Mat, D. J. L., Le Feunteun, S., Michon, C., Souchon, I., In vitro digestion of foods using pH-stat and the INFOGEST protocol: Impact of matrix structure on digestion kinetics of macronutrients, proteins and lipids. Food Research International 2016, 88, Part B, 226-233.

[16] Liu, X., Blouin, J. M., Santacruz, A., Lan, A., et al., High-protein diet modifies colonic microbiota and luminal environment but not colonocyte metabolism in the rat model: the increased luminal bulk connection. American journal of physiology. Gastrointestinal and liver physiology 2014, 307, G459-470.

[17] Beaumont, M., Andriamihaja, M., Lan, A., Khodorova, N., et al., Detrimental effects for colonocytes of an increased exposure to luminal hydrogen sulfide: The adaptive response. Free radical biology \& medicine 2016, 93, 155-164.

[18] Godon, J. J., Zumstein, E., Dabert, P., Habouzit, F., Moletta, R., Molecular microbial diversity of an anaerobic digestor as determined by small-subunit rDNA sequence analysis. Applied and environmental microbiology 1997, 63, 2802-2813.

[19] Mayeur, C., Gratadoux, J. J., Bridonneau, C., Chegdani, F., et al., Faecal D/L lactate ratio is a metabolic signature of microbiota imbalance in patients with short bowel syndrome. PloS one 2013, 8, e54335.

This article is protected by copyright. All rights reserved. 
[20] Furet, J. P., Firmesse, O., Gourmelon, M., Bridonneau, C., et al., Comparative assessment of human and farm animal faecal microbiota using real-time quantitative PCR. FEMS microbiology ecology 2009, 68, 351-362.

[21] Dridi, B., Henry, M., El Khechine, A., Raoult, D., Drancourt, M., High prevalence of Methanobrevibacter smithii and Methanosphaera stadtmanae detected in the human gut using an improved DNA detection protocol. PloS one 2009, 4, e7063.

[22] Lyons, S. R., Griffen, A. L., Leys, E. J., Quantitative real-time PCR for Porphyromonas gingivalis and total bacteria. Journal of clinical microbiology 2000, 38, 2362-2365.

[23] Kozich, J. J., Westcott, S. L., Baxter, N. T., Highlander, S. K., Schloss, P. D., Development of a dualindex sequencing strategy and curation pipeline for analyzing amplicon sequence data on the MiSeq Illumina sequencing platform. Applied and environmental microbiology 2013, 79, 5112-5120.

[24] Magoc, T., Salzberg, S. L., FLASH: fast length adjustment of short reads to improve genome assemblies. Bioinformatics 2011, 27, 2957-2963.

[25] Caporaso, J. G., Kuczynski, J., Stombaugh, J., Bittinger, K., et al., QIIME allows analysis of highthroughput community sequencing data. Nature methods 2010, 7, 335-336.

[26] Schmittgen, T. D., Livak, K. J., Analyzing real-time PCR data by the comparative C(T) method. Nature protocols 2008, 3, 1101-1108.

[27] McMurdie, P. J., Holmes, S., Waste not, want not: why rarefying microbiome data is inadmissible. PLoS computational biology 2014, 10, e1003531.

[28] Tanabe, S., Suzuki, T., Wasano, Y., Nakajima, F., et al., Anti-inflammatory and Intestinal Barrierprotective Activities of Commensal Lactobacilli and Bifidobacteria in Thoroughbreds: Role of Probiotics in Diarrhea Prevention in Neonatal Thoroughbreds. Journal of equine science 2014, 25, $37-$ 43.

[29] Russell, W. R., Gratz, S. W., Duncan, S. H., Holtrop, G., et al., High-protein, reducedcarbohydrate weight-loss diets promote metabolite profiles likely to be detrimental to colonic health. The American journal of clinical nutrition 2011, 93, 1062-1072.

[30] Zhou, L., Fang, L., Sun, Y., Su, Y., Zhu, W., Effects of the dietary protein level on the microbial composition and metabolomic profile in the hindgut of the pig. Anaerobe 2016, 38, 61-69.

[31] Mu, C., Yang, Y., Luo, Z., Guan, L., Zhu, W., The Colonic Microbiome and Epithelial Transcriptome Are Altered in Rats Fed a High-Protein Diet Compared with a Normal-Protein Diet. The Journal of nutrition 2016, 146, 474-483.

[32] Windey, K., De Preter, V., Verbeke, K., Relevance of protein fermentation to gut health. Molecular nutrition \& food research 2012, 56, 184-196.

[33] Davila, A. M., Blachier, F., Gotteland, M., Andriamihaja, M., et al., Intestinal luminal nitrogen metabolism: role of the gut microbiota and consequences for the host. Pharmacological research : the official journal of the Italian Pharmacological Society 2013, 68, 95-107.

[34] Windey, K., De Preter, V., Louat, T., Schuit, F., et al., Modulation of protein fermentation does not affect fecal water toxicity: a randomized cross-over study in healthy subjects. PloS one 2012, 7, e52387.

[35] Cummings, J. H., The large intestine in nutrition and diseases, Danone Institute, Brussels 1997, pp. 15-47.

[36] Blachier, F., Mariotti, F., Huneau, J. F., Tome, D., Effects of amino acid-derived luminal metabolites on the colonic epithelium and physiopathological consequences. Amino acids 2007, 33, 547-562.

[37] Macfarlane, G. T., Cummings, J. H., The control and consequences of bacterial fermentation in the human colon. J appl Bacteriol. 1991, 6, 443-459.

[38] Scott, K. P., Gratz, S. W., Sheridan, P. O., Flint, H. J., Duncan, S. H., The influence of diet on the gut microbiota. Pharmacological research : the official journal of the Italian Pharmacological Society 2013, 69, 52-60.

[39] David, L. A., Maurice, C. F., Carmody, R. N., Gootenberg, D. B., et al., Diet rapidly and reproducibly alters the human gut microbiome. Nature 2014, 505, 559-563.

This article is protected by copyright. All rights reserved. 
[40] Wu, G. D., Chen, J., Hoffmann, C., Bittinger, K., et al., Linking long-term dietary patterns with gut microbial enterotypes. Science 2011, 334, 105-108.

[41] Handlogten, M. E., Hong, S. P., Westhoff, C. M., Weiner, I. D., Apical ammonia transport by the mouse inner medullary collecting duct cell (mIMCD-3). American journal of physiology. Renal physiology 2005, 289, F347-358.

[42] Eklou-Lawson, M., Bernard, F., Neveux, N., Chaumontet, C., et al., Colonic luminal ammonia and portal blood L-glutamine and L-arginine concentrations: a possible link between colon mucosa and liver ureagenesis. Amino acids 2009, 37, 751-760.

[43] Blachier, F., Davila, A. M., Mimoun, S., Benetti, P. H., et al., Luminal sulfide and large intestine mucosa: friend or foe? Amino acids 2010, 39, 335-347.

[44] Cani, P. D., Van Hul, M., Novel opportunities for next-generation probiotics targeting metabolic syndrome. Current opinion in biotechnology 2015, 32, 21-27.

[45] Gevers, D., Kugathasan, S., Denson, L. A., Vazquez-Baeza, Y., et al., The treatment-naive microbiome in new-onset Crohn's disease. Cell host \& microbe 2014, 15, 382-392.

[46] Garcia Rodenas, C. L., Lepage, M., Ngom-Bru, C., Fotiou, A., et al., Effect of Formula Containing Lactobacillus reuteri DSM 17938 on Fecal Microbiota of Infants Born by Cesarean-Section. Journal of pediatric gastroenterology and nutrition 2016, 63, 681-687.

[47] Reichardt, N., Duncan, S. H., Young, P., Belenguer, A., et al., Phylogenetic distribution of three pathways for propionate production within the human gut microbiota. The ISME journal 2014, 8, 1323-1335.

[48] Moore, W. E., Holdeman, L. V., Human fecal flora: the normal flora of 20 Japanese-Hawaiians. Applied microbiology 1974, 27, 961-979.

[49] Roager, H. M., Hansen, L. B., Bahl, M. I., Frandsen, H. L., et al., Colonic transit time is related to bacterial metabolism and mucosal turnover in the gut. Nature microbiology 2016, 1, 16093.

[50] Derrien, M., Belzer, C., de Vos, W. M., Akkermansia muciniphila and its role in regulating host functions. Microbial pathogenesis 2016.

[51] Dao, M. C., Everard, A., Aron-Wisnewsky, J., Sokolovska, N., et al., Akkermansia muciniphila and improved metabolic health during a dietary intervention in obesity: relationship with gut microbiome richness and ecology. Gut 2016, 65, 426-436.

[52] Everard, A., Belzer, C., Geurts, L., Ouwerkerk, J. P., et al., Cross-talk between Akkermansia muciniphila and intestinal epithelium controls diet-induced obesity. Proceedings of the National Academy of Sciences of the United States of America 2013, 110, 9066-9071.

[53] Derrien, M., Vaughan, E. E., Plugge, C. M., de Vos, W. M., Akkermansia muciniphila gen. nov., sp. nov., a human intestinal mucin-degrading bacterium. International journal of systematic and evolutionary microbiology 2004, 54, 1469-1476.

[54] Vandeputte, D., Falony, G., Vieira-Silva, S., Tito, R. Y., et al., Stool consistency is strongly associated with gut microbiota richness and composition, enterotypes and bacterial growth rates. Gut 2016, 65, 57-62.

[55] Zhang, S., Ren, M., Zeng, X., He, P., et al., Leucine stimulates ASCT2 amino acid transporter expression in porcine jejunal epithelial cell line (IPEC-J2) through PI3K/Akt/mTOR and ERK signaling pathways. Amino acids 2014, 46, 2633-2642.

[56] Cummings, J. H., Hill, M. J., Bone, E. S., Branch, W. J., Jenkins, D. J., The effect of meat protein and dietary fiber on colonic function and metabolism. II. Bacterial metabolites in feces and urine. The American journal of clinical nutrition 1979, 32, 2094-2101.

[57] Terada, T., Shimada, Y., Pan, X., Kishimoto, K., et al., Expression profiles of various transporters for oligopeptides, amino acids and organic ions along the human digestive tract. Biochemical pharmacology 2005, 70, 1756-1763.

[58] Hirst, B. H., Dietary regulation of intestinal nutrient carriers. The Proceedings of the Nutrition Society 1993, 52, 315-324.

This article is protected by copyright. All rights reserved. 
[59] Greenfield, J. R., Farooqi, I. S., Keogh, J. M., Henning, E., et al., Oral glutamine increases circulating glucagon-like peptide 1, glucagon, and insulin concentrations in lean, obese, and type 2 diabetic subjects. The American journal of clinical nutrition 2009, 89, 106-113.

[60] Gameiro, A., Reimann, F., Habib, A. M., O'Malley, D., et al., The neurotransmitters glycine and GABA stimulate glucagon-like peptide-1 release from the GLUTag cell line. The Journal of physiology 2005, 569, 761-772.

[61] Jiang, Y., Rose, A. J., Sijmonsma, T. P., Broer, A., et al., Mice lacking neutral amino acid transporter B(0)AT1 (Slc6a19) have elevated levels of FGF21 and GLP-1 and improved glycaemic control. Molecular metabolism 2015, 4, 406-417.

[62] Rasoamanana, R., Darcel, N., Fromentin, G., Tome, D., Nutrient sensing and signalling by the gut. The Proceedings of the Nutrition Society 2012, 71, 446-455.

[63] Meier, J. J., Gethmann, A., Gotze, O., Gallwitz, B., et al., Glucagon-like peptide 1 abolishes the postprandial rise in triglyceride concentrations and lowers levels of non-esterified fatty acids in humans. Diabetologia 2006, 49, 452-458.

\section{AUTHOR CONTRIBUTIONS}

M. B., D. J. and V. D: experiments, data acquirement and analysis and manuscript writing. A. H., F. K., B. G., C. M., C. C. and A.-M. D: data acquirement. D. M., S. Le F.: food matrix design and production; S. M.: 16S rDNA libraries and high throughput sequencing. D. T.: Study design I. S., C. M.: food matrix design, study design. G. F., F. B. and M. L.: study design and manuscript writing.

\section{ACKNOWLEDGMENTS}

This work was funded by a French governmental ANR grant through the Idex Alias program ANR11-IDEX-0003-02, which also covered Daphné Jaoui, Martin Beaumont and Damien Mat PhD fellowships. The authors are grateful to D. Rousseau-Ralliard (UMR Biologie De la Reproduction, INRA) for the technical support for fatty acid composition analysis, to the INRA MIGALE bioinformatics platform (http://maiage.jouy.inra.fr/?q=fr/migale) for providing computational resources and support. High-throughput sequencing has been performed by the NGS platform of the Institut Curie, supported by the grants ANR-10-EQPX-03 and ANR10-INBS-09-08 from the Agence Nationale de le Recherche (investissements d'avenir) and by the Canceropole Ile-de-France.

\section{CONFLICT OF INTEREST STATEMENT}

None of the authors declare conflict of interest for this work.

This article is protected by copyright. All rights reserved. 


\section{FIGURE LEGENDS}

Figure 1: Microbiota structure assessed by qPCR. LFE: liquid fine emulsion, GCE: gelled coarse emulsion, Caecum MM: caecum mucus-associated microbiota. Cells count/gram are represented for each probe. Boxplots represent median, and quartiles (Q25\% and Q75\%). Mean ranks were compared with Mann-Whitney test. *: $\mathrm{p}<0.05, * *: \mathrm{p}<0.01$. LFE: $\mathrm{n}=8$, GCE: $\mathrm{n}=8$.

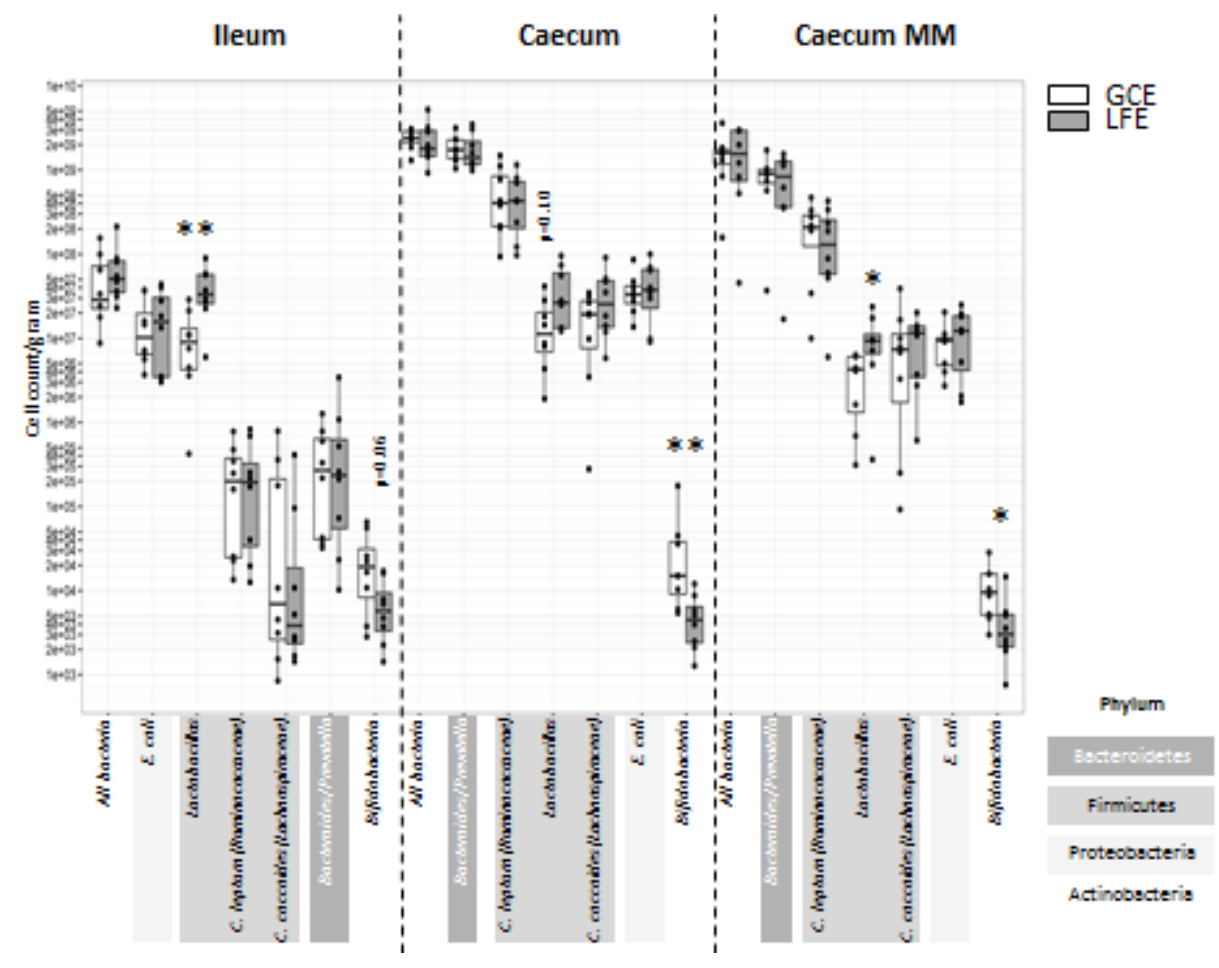

This article is protected by copyright. All rights reserved. 
Figure 2: 16S rDNA microbiota composition in the ileum. LFE: liquid fine emulsion, GCE: gelled coarse emulsion. A: Most abundant Phyla, B: Most abundant families from the Firmicutes, inset: species of the Lactobacillus genus impacted by the diet. The Y-axis represents sequences normalized to the total number of reads. Normalized counts were compared with Wald test, Benjamini Hochberg correction. *: $\mathrm{p}<0.05$. LFE: $\mathrm{n}=7$, GCE: $\mathrm{n}=4$.
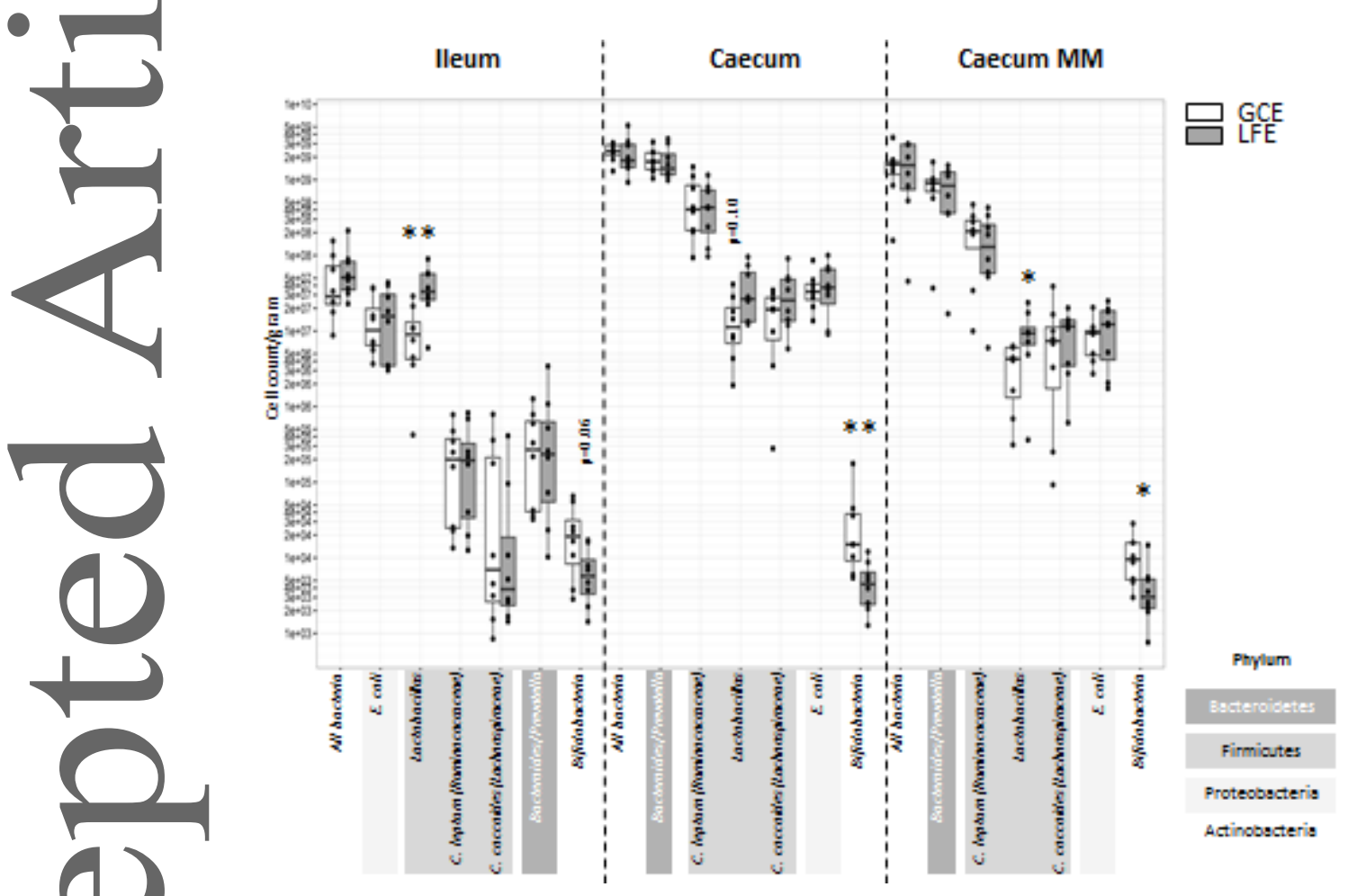

This article is protected by copyright. All rights reserved. 
Figure 4: 16S rDNA microbiota composition in the caecum mucus. LFE: liquid fine emulsion, GCE: gelled coarse emulsion. A: Multidimensional scaling showing $\beta$-diversity calculated on normalized sequences counts using data Jaccard distances. B: Most abundant genera from the Lachnospiraceae family, inset: OTUs of the Lachnospiraceae impacted by the diet. C: OTUs from the Ruminococcaceae impacted by the diet. D: OTUs from the Bacteroidales order impacted by the diet. The Y-axis represents sequences normalized to the total number of reads. Normalized counts were compared using Wald test and Benjamini Hochberg correction. *: $\mathrm{p}<0.05$. LFE: $\mathrm{n}=5$, GCE: $\mathrm{n}=5$.

A
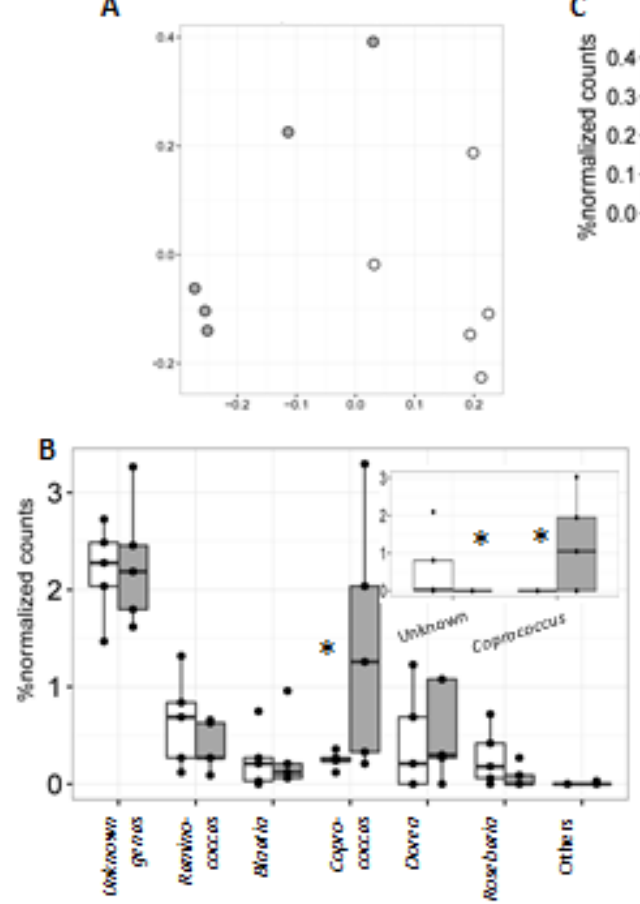

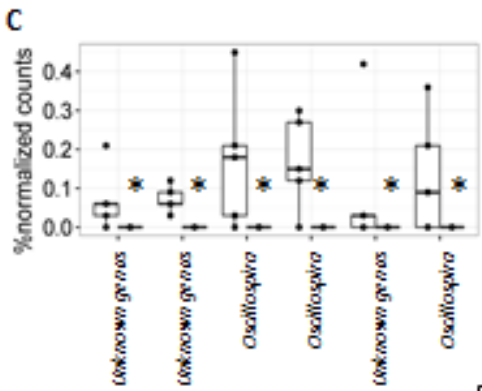

D

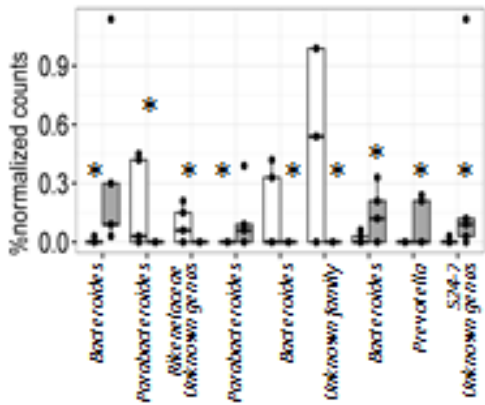

This article is protected by copyright. All rights reserved. 
Figure 5: Gut peptide mRNA expression levels in large intestine and portal blood concentration.

LFE: liquid fine emulsion, GCE: gelled coarse emulsion. A: Glucagon $(G c g)$ relative mRNA expression level in the caecum and colon. B: Glucagon-like peptide-1 (GLP-1) concentration in portal plasma. C: Peptide YY (Pyy) relative expression level in the caecum and colon. Gene expression data were normalized relative to levels seen in LFE group of each segment. Values represented are mean \pm SEM. Means were compared with Mann-Whitney test. *: $\mathrm{p}<0.05$. LFE: $\mathrm{n}=8$, GCE: $\mathrm{n}=8$.

A

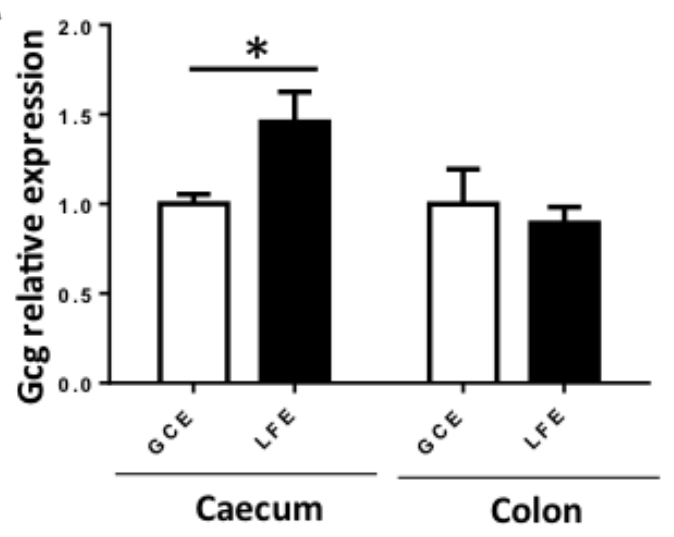

B

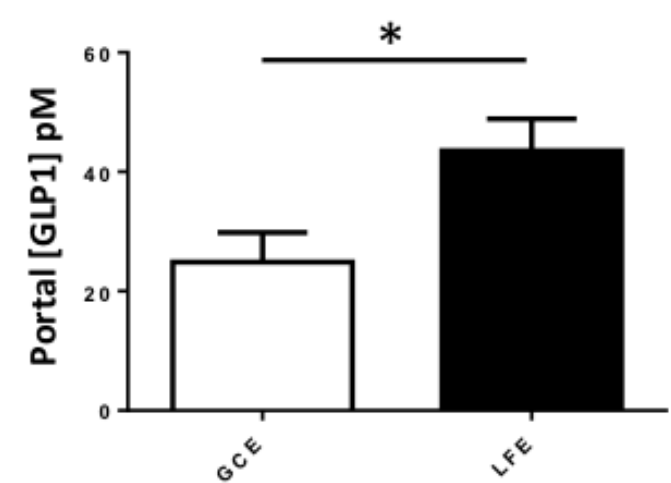

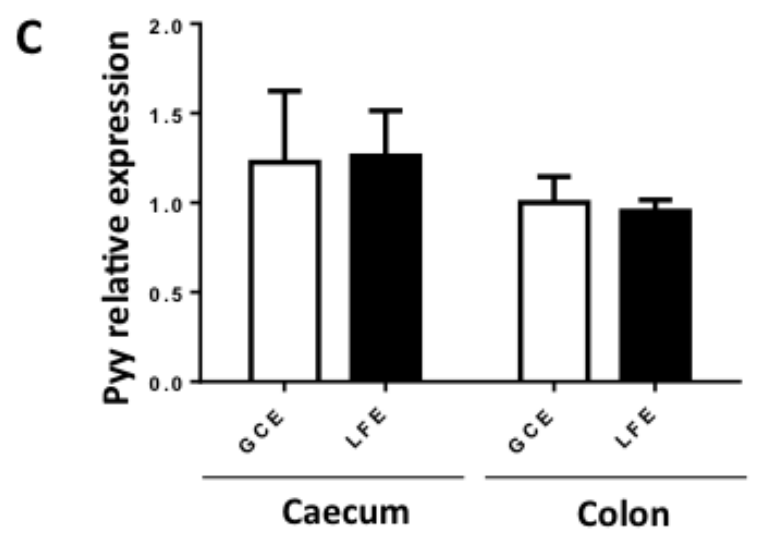

This article is protected by copyright. All rights reserved. 
Figure 6: Schematic view of the impact of diet structure on the animal gastrointestinal tract, peripheral organs and gut microbiota. LFE: liquid fine emulsion, GCE: gelled coarse emulsion. LFE diet increased Lactobacillaceae and decreased Bifidobacteria abundance (1) and enhanced expression of AA transporters (2) in the ileum. In the caecum, LFE diet increased Lactobacillus and Coprococcus, decreased A. municiphila, (3) and is associated to higher $\beta$-diversity of the caecum mucus-associated bacteria (4). In parallel, caecum content was augmented in the LFE as well as the isovalerate total content and the total urease and cystein desulfhydrase activities (5). LFE diet also increased glucagon expression in the caecum, together with an elevated level of GLP-1 in portal plasma (6). No modifications of food intake or of body weight gain were observed between the two diets (7).
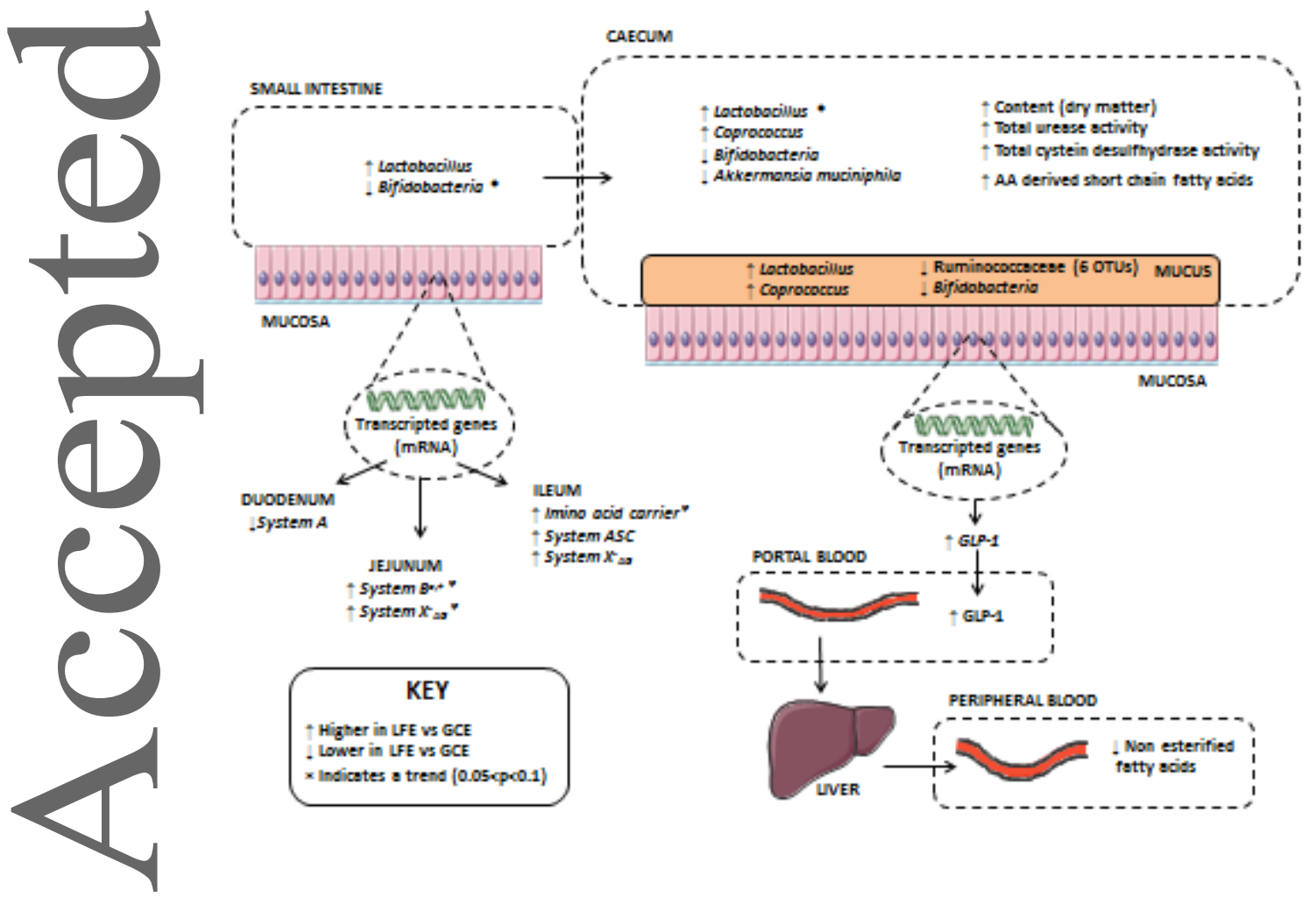

This article is protected by copyright. All rights reserved. 


\section{TABLES}

Table 1: Composition of the experimental diet. * indicates ingredients included in the lipid-protein matrices of identical composition but with different structures in the LFE liquid fine emulsion and GCE gelled coarse emulsion.

\begin{tabular}{ll} 
Ingredients & $g / k g$ (dry matter) \\
\hline Whey protein isolate* & 214.9 \\
Rapeseed oil* & 110.2 \\
Corn starch & 489.7 \\
Sucrose & 79.7 \\
Cellulose & 50 \\
Choline & 2.3 \\
Vitamin mixture, AIN 93-V & 10 \\
Mineral mixture, AIN 93-M & 35 \\
Energy & \\
Energy density (kJ/g) & 16.7 \\
Carbohydrate (\% energy) & 53 \\
Protein (\% energy) & 20 \\
Fat (\% energy) & 26 \\
\hline
\end{tabular}


Table 2: Bacterial metabolites in caecum content. LFE: liquid fine emulsion; GCE: gelled coarse emulsion, SCFA: short chain fatty acids, AA: amino-acid. AA-derived SCFA includes isobutyrate, isovalerate and valerate. Values are mean \pm SEM. Means were compared with Mann-Whitney test, NS: not statistically significant $(\mathrm{p}>0.05)$.

\begin{tabular}{llll} 
& & Caecum & \\
& GCE $(\mathrm{n}=8)$ & LFE $(\mathrm{n}=7-8)$ & $P$ value \\
\hline Content characteristics & & & \\
Content weight $(\mathrm{g})$ & $1.68 \pm 0.05$ & $2.14 \pm 0.10$ & $\mathbf{0 . 0 0 3}$ \\
Water $(\%)$ & $77.06 \pm 0.84$ & $75.25 \pm 0.92$ & NS \\
Total amount in the caecum content $(\mu \mathrm{mol})$ & & & \\
Acetate & $40.04 \pm 4.49$ & $48.12 \pm 3.93$ & NS \\
Propionate & $13.25 \pm 1.40$ & $15.15 \pm 0.62$ & NS \\
Butyrate & $6.19 \pm 0.80$ & $7.72 \pm 0.73$ & NS \\
Isobutyrate & $0.68 \pm 0.08$ & $0.80 \pm 0.05$ & NS \\
Isovalerate & $1.34 \pm 0.21$ & $1.96 \pm 0.17$ & $\mathbf{0 . 0 4 9}$ \\
Valerate & $1.34 \pm 0.15$ & $1.54 \pm 0.06$ & NS \\
Total SCFA & $62.84 \pm 6.83$ & $75.29 \pm 5.20$ & NS \\
AA derived SCFA & $3.35 \pm 0.39$ & $4.30 \pm 0.19$ & $\mathbf{0 . 0 4 9}$ \\
Ammonia & $4.95 \pm 0.85$ & $5.85 \pm 0.85$ & NS \\
Sulfide & $0.25 \pm 0.02$ & $0.43 \pm 0.12$ & NS \\
Total enzymatic activity in caecum content & & & \\
Cystein desulfhydrase $(\mu m o l$ sulfide/min) & $0.20 \pm 0.02$ & $0.27 \pm 0.03$ & $\mathbf{0 . 0 4 9}$ \\
Urease $(\mu m o l$ ammonia/min) & $2.39 \pm 0.27$ & $3.51 \pm 0.31$ & $\mathbf{0 . 0 2 8}$ \\
\hline
\end{tabular}

This article is protected by copyright. All rights reserved. 
Table 3: Gene expression of AA and peptide transporters in various regions of the small intestine. LFE: liquid fine emulsion; GCE: gelled coarse emulsion. Values are mean \pm SEM. Means were compared with Mann-Whitney test, NS: not statistically significant $(\mathrm{p}>0.05), P$ values $<0.10$ are shown. In each region, data were normalized relative to levels seen in GCE group.

Duodenum

\section{Transporter name}

(peptides or AA transported)
Jejunum

Ileum

GCE

LFE

$P$ value

GCE

LFE

$P$ value

GCE

LFE

$P$ value

\section{Apical transporters}

Peptide transporter PEPT1 $(d i \&$ tri

$1.00 \pm 0.08$

$0.98 \pm 0.12 \quad$ NS

$1.00 \pm 0.15$

$1.13 \pm 0.16 \quad \mathrm{NS}$

$1.00 \pm 0.06$

$0.94 \pm 0.05$

NS peptides)

\section{System B $\mathbf{B}^{\mathbf{0}}$ (neutral AA)}

$$
1.00 \pm 0.10
$$

$0.85 \pm 0.07 \quad \mathrm{NS}$

$1.00 \pm 0.06$

$1.18 \pm 0.12 \quad \mathrm{NS}$

$1.00 \pm 0.08 \quad 1.20 \pm 0.07$

NS

Imino acid carrier (Imino acids,

$1.00 \pm 0.01$

$0.87 \pm 0.09 \quad \mathrm{NS}$

$1.00 \pm 0.07$

$1.19 \pm 0.12 \quad \mathrm{NS}$

$1.00 \pm 0.06$

$1.26 \pm 0.12$

System $\mathbf{B}^{\mathbf{0},+}$ (neutral and cationic AA)

$1.00 \pm 0.11$

$1.20 \pm 0.10 \quad \mathrm{NS}$

$1.00 \pm 0.10$

$1.26 \pm 0.09$

0.092

$1.00 \pm 0.09 \quad 1.13 \pm 0.13$

NS

System ASC (alanine, serine, cystine,

$1.00 \pm 0.08$

$0.92 \pm 0.12 \quad \mathrm{NS}$

$1.00 \pm 0.08$

$1.05 \pm 0.1$

NS

$1.00 \pm 0.05 \quad 1.23 \pm 0.06$

0.013 threonine, glutamine)

System bo,+(cationic AA, cystine)

$1.00 \pm 0.04$

$0.92 \pm 0.04 \quad \mathrm{NS}$

$1.00 \pm 0.07$

$0.93 \pm 0.05 \quad$ NS

$1.00 \pm 0.05 \quad 1.08 \pm 0.05$

System $\mathbf{X}_{\mathbf{A G}}^{-}$(anionic AA)

Received: 23/01/2017; Revised: 10/04/2017; Accepted: 25/04/2017

This article has been accepted for publication and undergone full peer review but has not been through the copyediting, typesetting, pagination and proofreading process, which may lead to differences between this version and the Version of Record. Please cite this article as doi: 10.1002/mnfr.201700078. This article is protected by copyright. All rights reserved. 
Table 4: Peripheral plasma metabolites, cumulated food intake, body weight gain and adiposity

of rats. LFE: liquid fine emulsion; GCE: gelled coarse emulsion, NEFA: non-esterified fatty acids.

Values are mean \pm SEM.* Adiposity $=($ Body fat $/$ body weight $) * 100$. Means were compared with

Mann-Whitney test, NS: not statistically significant $(\mathrm{p}>0.05)$

\begin{tabular}{llll} 
& GCE $(\mathrm{n}=7-8)$ & LFE $(\mathrm{n}=7-8)$ & $P$ value \\
\hline Cumulated food intake $(k J)$ & $13.90 \pm 0.43$ & $14.50 \pm 0.47$ & NS \\
Body weight gain $(g)$ & $82.21 \pm 4.80$ & $93.11 \pm 7.55$ & NS \\
White pad fat $(g)$ & $48.05 \pm 5.63$ & $45.89 \pm 3.76$ & NS \\
Adiposity* $(\%)$ & $14.06 \pm 1.03$ & $12.86 \pm 0.65$ & NS \\
Peripheral plasma metabolites & & & \\
Glucose $(\mathrm{g} / \mathrm{L})$ & $10.09 \pm 0.65$ & $10.52 \pm 0.69$ & NS \\
Triglyceride (mmol/L) & $1.59 \pm 0.29$ & $2.05 \pm 0.28$ & NS \\
Total cholesterol (mmol/L) & $1.74 \pm 0.07$ & $1.78 \pm 0.08$ & NS \\
Total HDL (mmol/L) & $0.84 \pm 0.08$ & $0.93 \pm 0.06$ & NS \\
NEFA (mmol/L) & $0.21 \pm 0.03$ & $0.12 \pm 0.01$ & $\mathbf{0 . 0 5}$ \\
\hline
\end{tabular}

Received: 23/01/2017; Revised: 10/04/2017; Accepted: 25/04/2017

This article has been accepted for publication and undergone full peer review but has not been through the copyediting, typesetting, pagination and proofreading process, which may lead to differences between this version and the Version of Record. Please cite this article as doi: 10.1002/mnfr.201700078.

This article is protected by copyright. All rights reserved. 